\title{
The Criteria and the Characterizing Reports in the Objectivist and Subjectivist Point of View
}

\section{Doi:10.5901/ajis.2015.v4n3s1p374}

\author{
Gentjana Dedja
}

\begin{abstract}
The aim of this study is to submit different theories on the nation and to realize the access on its determining criteria. The notion of the nationality describes the affiliation of an individual to a nation. A nation cannot change its symbols, the language and the culture as they determine its existence. The nation requires a long period of time to be created. In wide territories there are individuals of various nationalities, with language, culture and different habits. Many researchers agree with the theory that the nation is a modern phenomenon, but they add an important objection; they argument that the nations did not appear from nowhere, but the pre modern ethnic associations are transformed into national identities. The modern societies nowadays are transformed in "multi ethnic societies".
\end{abstract}

Keywords: nation, nationality, ethnicity, language, culture.

\section{Introduction}

Nationality describes the affiliation of an individual to a nation. During their historic process of formation societies are organized in extended families and tribes, as well as the wider community thanks to more comprehensive collective identities such as ethnic, religious, city-state, provincial, etc. The nation, as sociological category is a relatively new source of collective identity that appeared in Europe since the XVIIIth century. Naturally, the idea of a nation appeared as development and continuity in the course of people's need to belong to any "imagined community". The need to belong to any group and to join its members is not something new in the history of mankind. However, what is new is the phenomenon of national identity itself. The new notion about this is the political and geographical dimension, as the nationalism alleges. Unlike other forms of collective identitetities, tha nation is a group of people who are politically aware and have a common sense of belonging due to certain features and circumstances, which will be discussed below.

When theoretitians (historians, anthropologs, sociologists etc.,) try to define a nation, they usually analyze the origine of the source meaning and its descent. What they look for is to find the historical and social context which has replace the older form of the group identity with the national identity. Some argue that it has been the modernity process itself which has totally replace the dinastic and religious authorities and has forced the creation of a anew legitimity for more inclusive central authorities. Other researchers agree with the primar proposal of the modernists; according to them the nation is a modern phenomenon, but they add a very inportant objection to this; they argument that the nations did not come from nowhere, but the pre modern relations are transformed into national identities (Smith:1988). Meanwhile, others see the nation formation as a more subjective process. They argue that the national identity is the people's desire to live in a community and to belong to the same nation. This solidarity, which leads to the nation formation, is stated to be a form of an "everyday referendum". (Renan: 1990)

\section{A General Theoretical View}

The main dilema on the discussions about the nation and its theory is related to the determination that up to what extend the nation and nationalism are modern phenomenons. There are different theories about the nation; which means these theories stand between the modernist and ethno- symbolist perspectives. In Albanian language, according to the vocabulary we find the word nation ( a stable community of people, formed historically and based on the language communion, territory, economic life and psychic formation, which are all presented in the culture communion"), population ( a community of people who live as a social and political community in a country or a state; the inhabitants of a place or region; the classes and the wide levels which constitute the basis of a society and its development during a certain period"; but we also find uses as nationality, nation etc.

The idea that the nations as social construction are developed on myths is proposed from two authors; Eric Hobsbawm and Benedict Anderson. Hobsbaam stated that the "ongoing" and "uniform" history often is a fiction based on 
half mythical characters, documents and false symbols as the flag and images that aim to arouse nationalistic feelings. (Hobsbawm and Ranger: 1983).

Anderson (2006) proposed that nations are "imaginary communities based on myths and symbols. The idea itself of the common national descent is more a myth than a reality. It is not sure that a certain pure nation that comes from same predecessors keeping in mind that populations have migrated in different territories, have married into different ethnic groups so they are mixed through the different processes. This makes it harder to prove the common origine. People have mixed origines, but their ideas for the common past are more immagined, so they are more myths than facts. A myth becomes distiguishable for example in the idea of th epure ethnic origine in the Balcan nations. Keeping in mind the high level of the mix marriages, the fact that tha reliogios identity has been primary for a long time, the migration of th epeople and other demographic and social processes, it seem as this term is polemyzing; the serbians, croatians, bosnians, may think that they have different ethnicities, but they are southern sllavics, speak the same dialects of a language, their descent is sllavic, turkish, hungarian, albanian and latin mixture.

The modernists who talk about nations as constructed and immagined communities do not necessarily mean the nations "falcity" or that they are immaginary. More clearly, this idea is more related to Gellner and Hobsbawm but is refused by Anderson. (Anderson 2006:6). The theoreticians of this line have defined the nation in various ways by using different criteria to explain its characteristics, the definition and its processes. The common features of the populations are seen as main characteristics of a nation and basically they are descent, language, culture and common religion. Nevertheless, these criteria are very questionable as besides the unity effect they might have separation effects too. For example, as the same language may include in one nation various populations, regarding other features (religious, cultural etc.,) it may exclude other populations totally homogenous for the same characteristics, but without the same language.

On the other side, the common language is not enough to create the common national identities, despite other common features as the same origin; ethic affiliation etc. An illustration of this is the case of the Southern Slavic (Croatians, Bosnians, and Serbians). Some languages are different and excluding for the national identity of some nations as it is the case with the Albanian language, which is very special to Albanians and excludes everybody else that do not speak Albanian and so on. However, different nations may have the same language, (for example the English) but are not considered members of the same nation, but on the other hand one nation might speak some languages as it is the case with the Indian nation. The language is seen as the most important "mark" of the nation, especially with the Eastern Europe, but in other cases it may be seen as separation factor or at least not relevant in a nation creation. The same analyses may be used to examine the other characteristics of the nations as the culture, religion and their relations with the national identity.

\section{Methodology}

The methodology used in this study has a complex character which means a series of elements and techniques, which are based on theoretical and practical experience to the theories of a nation definition. The theoretical material will serve as a comparison of the thoughts, ideas and views of the phenomenons under review. The theoretical approaches are based on the past of populations as a base for their creations and are very difficult as it is hard to take as a creation component only one component. The direct interviews serve us to create an idea for the concept of the nation through different generations, often by interpretions based on sociologic bases of the society separation according to the age variable.

The relation language- nation

Ehtnicity seen in the first meaning of the word, a group that speaks the asme language, or a anthropologic, linguistic, historical, political and economical group, so with a special culture, aims in its development to achieve the level of a nation, meanwhile the nation itself aims to become a state which would support the ethnicity. During these processess there are mixtures of factors involved such as the definition of the territory, the compactivity of the unit, the preservation and development of the language and the culture (R. Ismajil, 1991:9). However, often certain populations may not speak the offcial language of their ethnic belonging. This is denied from the foreign and separatist impacts and may disappear, or die by adding to the number of dead languages, non functional and not used any more. Very often we encounter opposite attitudes related to the relation language and nation. The attitude according to which " the nation exists because there is one language* the identity of the nation comes and is expressed from the language*, and the opposite stand; the nation exists, so it needs a language, which means that the national identity exists prior to language, and the language comes as an element that accompanies the nation. 
At the end of the first spanish grammar A. Nebriha writes: "The language marks the borders of the empire". With the today political and social development, with the opening to a more global society the realtions between the state and the territory are more mutually interconected. The nation appears to be changable in its ethnicity, some times as a community that exists prior to the state and makes it be, and sometimes as a community which becomes a nation by the state through the official language, certain language politics which serve the language institutionalization.

The language is the main feature that enables the characterization and identification of ethnicity, up to the level that "Without language there is no fatherhood", even though there are cases where we might see language disappear but not the ethnic identity. The language is the most important feature as it relates directly to the way of thinking and general culture, it is never just a language.

\section{Objectivism Point of View}

Some authors explain the formation of the nations with criteria that we may call "objective" as industrialization, the same past, race, language, religion etc. According to this point of view, people's identification as part of an imagined nation is made possible through some conditions that may be called "objective terms". The authors emphasize that the "objective terms" such as ethnicity, language, class, region, religious beliefs that impact the nations' creation are called factors. But, these authors do not agree on their degree of contribution in the formation of the national identities and their role in the nation's definition. That is why there are so many definitions of the word "nation" in the literature (Özkirimli 2000:58)

Other authors emphasize other "subjective terms" in their definitions of the nation, for example awareness, the people's approval to live together and so on. So, there are definitions of the nation that do not relate to the objective criteria, but the will of people to be part of a nation (Özkirimli 2000:58)

"Nations and nationalities are not natural, as they are not permanent features of the human conditions, but they have appeared gradually during the merge of industrial period. This does not mean that the explanations for the nations' creation are closely related to industrialism. In reality, this makes nations seem natural for the members of the industrial society. But, what is there in the transition period into industrialism that nations and nationalities became universal in this modern time?" (Gellner 2008: XXIII). For Gellnerin, nationalism is not an expression of the nations, classes or intelectual elite, and its roots are not found in the study of the nations, capitalism, classess or ideas. Gellner explained the creation of the nations with a casual connection according to which the circumstances in modernity as capitalism and industrialism condition the creation of nationalism, while nationalism conditions the creation of nations.

To explain this relation Gellner had to identify the main feature of modernity and then process an argument that demonstrates the functionality of nationalism in modernity. (Gellner 2008: XXI) Gellner understood modernity as a distinct form of culture and social organization. He considered that nationalism is in the function of modernity. While agreeing with Kedourie (2004) that nationalism is modern phenomenon and that it had developed nations, and not vice versa, Gellner did not agree that this happened thanks to the power of nationalism as an idea or often to the intellectual class as carrier of this idea. The idea of nationalism was a product, not the manufacturer of modernity. Its success is not attributed to his intellectual power, but its functions within the social moral order.

When it comes to the common past of the nation, it is usually meant the common ethnic affiliation, culture, history and so on. The idea that ethnicity is the ancestor of the nation, and the nation is based on the rediscovery and reinterpretation of ethnic background is suggested by Anthony $D$. Smith.

Brewton separates the two definitions for ethnicity: In a narrow sense the term ethnic accompanies the group of individuals that belong to the same mother tongue. In this case ethniticy equals linguage group. This definition may be objected due to the geographical, historical, racial, or linguistic (standard languages) distance.

Ethnicity is broadly defined as a group united by a complex of features; anthropological, political and historical, whose association is a system, a cultural structure. In this case the language is one of the features, while various features of the system are not developed equally to all individuals of the group. Almost all our interviewed community conceives ethnicity according to Brwton in both perspectives.

Ethnicity is defined as a group of people with cultural identity and / or the same language. The nation is formed by one or more ethnics and is a community much more awareness of ethnicity. Ethnicity is one of the most important aspects of cultural or social identity. Therefore, the term ethnicity is often used synonymously for the nation. But people with common ethnic affiliations can live in different states-nations and therefore can be treated as members of different nations. The authors agree regarding the impact of ethnicity, language and religion in the creation of nations. However, they do not agree on the extent to which they contributed to the formation of national identities and their importance or relation to the definition of the nation. 
Theoretical approaches that are based on the common past of the people as the basis for the creation of nations cause difficulties especially because it is difficult to get one of the components of nation as a general criterion. Let's take language, religion or ethnicity, for example. Any of these alone is not enough to create a sense of national identity. Moreover, in some nations, language, religion and / or ethnicity are disintegrating factors. That is why some nationalisms do not use one of them or all the three together as integral elements of national identity. Although this approach is valid in terms of many nations in the world, it has some weaknesses: it is proved that ethnicity is not necessary, nor sufficient term of the sense of nationality. Ethnicity can be a valuable basis to create a nation in the case of the Japanese, Armenians, Greeks, Albanians, but it played no role in the creation of modern nations, such as the French nation that is Celtic, Iberian and German or the German nation that is Germanic, Celtic and Slavic or American nation is a melting pot of whatever ethnicities and cultures. In some cases, even the perception of shared ethnicity does not guarantee the unified national identity.

The process of the national identity is inclusive and exclusive too. It includes nations with at least some common characteristics and excludes some others, as the nation defines itself by being distinguished by "the other" especially from the neighbor nation. "Ours" refers to everything that is percepted and considered as a member (hero etc.,) or an important symbol (myth, toponyms) of a certain nation. All the nations have in common the "other" perception, and often of the opponent.

The existence of the opponent that represents the enemy of the nation contributes the rise of the national feeling. The common suffering has a powerful strength to unite a nation, while the common enemy is an undeniable force of solidarity and mobilization. Nationalism often has appeared when a nation feels threatened from the enemies percepted as such. This may be illustrated with the example of the American nationalism and its opponents, from the Spanish and British imperialism, nazism, communism and nowadays the Islamic fondamentalism. The nationalisms of the Central and Eastern Europe, which are regions where the regional empires (Ottoman, Russian and Austro-Hungarian) have ruled from centuries, the enemy is defined with these foreign invaders. However, in certain cases, the opponent is from inside and not necessarily from outside.

\section{The Subjectivism Point of View}

The nation may be determined as a community that fullfills at least some of the objective terms mentioned above, which means that these terms enable the creation of the nation.

However, the drawbacks of the viewpoint that defines the nation with these objective terms is that there is no single criterion or set of criteria that are part of all nations. Certain features can be met by certain nations, but not by all. Therefore, it can hardly be spoken only for objective criteria in the analysis of a nation's creation. Alternatively there is a subjectivistic approach that emphasizes that the nation is a group of people who think as a nation thanks to their desire and decision to live together and in social solidarity.

Theoreticians of this view take a different attitude and argue that the nation is created by a more subjective process, which is the collective awareness, when people link themselves to the national identity and homeland. Philosopher John Stuart Mill wrote that the nation is made of people who agree to live under a common government .. "(Mill 1910). This approach is supported by the historian Ernest Renan, who in the XIXth century wrote that the connection to a nation is a matter of solidarity and common feelings, clearly expressed desire to continue living together. "A nation is thought of as the past, but is expressed in the present ... clearly expressed desire to continue a common life." (Renan, 1990)

Nevertheless, the subjective point of view has its drawbacks. It assumes that nations are created from nothing and does not take into consideration the previous objective terms that enable the manifestation of this process (at least in the Europian context) which are the trade, communication and the facilitated travelling, the loyalty to the central authorities that has replaced the loyalty to the local authorities especially the middle class. Furthermore, the existance of the enemy that represents the national enemy contributes to the rise of national feeling.

\section{Conclussions}

The definition of the nation is not an easy task, from the cause of its complexity and the opposite meanings of its characteristic features. Through the analyzes of a questionnaire conducted in the Albanian society we noticed that mostly the new generation has generalized the idea of the nation on its subjective creation. They state that the homeland is the flag, the language and the identity in addition to the social solidarity. The flag is called unsubstituted as a nation's symbol, 
but the language is diversatile in the global movement. The opening to a global society creates the opening in this point of view, where in most of the cases the idea of the homeland comes as changed. Very often the interviewed young individuals state that they create the homeland where they feel better and valued for the job performance, even in most of the cases they accept that they abandon the physical natural areas for a better life. The middle age generation often expressess ambiguous attitude on the definition of the homeland, while the old age generation can not concept the separated homeland in physical and moral view, and they are closer to objective point of view. A better approach would be if we see those as nonexcluding parts of each other. "The nation may be defined as a community which fullfills the objective terms (as the industrialism or the common memories) and if it believes that it is a nation thanks to these common features" (Archard 2000:159)

\section{References}

Anderson B., (2006) Imagined Communities, Reflections on the Origin and Spread of Nationalism. London, New York: Verso.

Archard, D., (2000) Nationalism and political theory. In O'Sullivan, N., ed. Political Theory in Transition. London and Neë York: Routledge, pp.155-171.

Giddens, A., (2005). The Consequences of Modernity. Cambridge: Polity.

Day, G. and Thompson, A., (2004) Theorising Nationalism. New York: Palgrave Macmillan.

Hearn, J., (2006) Rethinking nationalism, a critical introduction. New York: Pallgrave Macmillian

Hastings, A., (1997) The Construction of nationhood, ethnicity, religion and nationalism. Cambridge: Cambridge University Press

Hutchinson, J. and Smith A.D., eds., (1994) Nationalism, Oxford, Neë York: Oxford University Press

Hobsbaëm, E. and Ranger, T., (eds), (1983) The Invention of Tradition. Cambridge: Cambridge

Smith, A.D. (1988) The Ethnic Origins of Nations. Oxford: Blackwell.

Smith, A. D., (1991) National Identity. England: Penguin Books.

Smith, A. D., (1995) Nations and Nationalism in a Global Era. Cambridge: Polity Press.

Smith, A.D., (1999) Myths and Memories of the Nation. Oxford: Oxford University Press.

Spencer, P. and Wollman, H., (2006) Nationalism a Critical Introduction. London: Sage Publications

Ismajli, R. Language and Ethnicity, ( 1991) Rilindja, Prishtine. 